Article

\title{
Experimental Study on Biomass Heating System in the Greenhouse: A Case Study in Xiangtan, China
}

\author{
Tao Huang ${ }^{1}$, Hongqiang $\mathrm{Li}^{1, *}$, Guoqiang Zhang ${ }^{1, *}$ and Feng $\mathrm{Xu}^{2}$ \\ 1 College of Civil Engineering, Hunan University, Changsha 410082, China; huangtao1613@hnu.edu.cn \\ 2 School of Architecture, Hunan University, Changsha 410082, China; fengxu@hnu.edu.cn \\ * Correspondence: lhq@hnu.edu.cn (H.L.); gqzhang@hnu.edu.cn (G.Z.); Tel.: +86-134-6944-4408 (H.L.); \\ +86-139-0731-7560 (G.Z.)
}

Received: 29 June 2020; Accepted: 13 July 2020; Published: 15 July 2020

\begin{abstract}
To meet the indoor heat load demand of greenhouses in China rural areas in winter, the authors proposed and designed a novel biomass heating system in greenhouses. The system uses biomass flue gas as the thermal working medium and heats the shallow soil inside the greenhouse through the buried flue gas-soil heat exchanger, thereby improving the indoor thermal environment of the greenhouse. To further study the heating system performance, we built up the heating experimental platform in a plastic greenhouse. Through testing the actual operation effect of the biomass heating system of the plastic greenhouse, no taking any heating measures system, the biomass heating system of the plastic greenhouse can improve the air average temperature and the soil average temperature $5.1^{\circ} \mathrm{C}$ and $8.2^{\circ} \mathrm{C}$, respectively. The greenhouse biomass heating system is very economical, compared with the greenhouse without heating system, which can bring a $105 \%$ excess return rate for farmers every year. This study has obvious significance to promote the sustainable development of rural agriculture and the efficient utilization of rural biomass resources.
\end{abstract}

Keywords: greenhouses heating; biomass energy; buried heat exchanger; greenhouse thermal comfort

\section{Introduction}

The development of rural agriculture in China is facing challenges since traditional agricultural planting methods are hard to produce considerable economic benefits, more and more farmers choose to abandon agricultural farming. However, the development of greenhouse planting technology is expected to improve this phenomenon. It breaks the time and space restrictions on people's demand for anti-season fruits and vegetables and meets the demand for the quality and diversity of agricultural products, which can promote the sustainability of rural agriculture and rural economy. It has also gradually become an important means for the Chinese government to promote and solve the three rural issues, consolidate the achievements of poverty alleviation, and achieve rural revitalization.

Currently, the quality of rural greenhouse facilities in China is uneven, because China is still a developing country. The operating mode of the greenhouse is extensive, and the accurate control of temperature and humidity in the greenhouse has not yet been achieved. The quality of indoor environmental control in the greenhouse needs to be improved, especially the indoor temperature closely related to plant growth [1]. Temperature is one of the most important factors affecting plant growth, including indoor air temperature and soil temperature [2]. However, the traditional greenhouse relies on the passive absorption of solar energy, that is, using the principle of the greenhouse effect to improve the temperature in the greenhouse, its regulation ability is poor, and it cannot effectively resist the long winter and continuous rainy and snowy weather. The traditional passive greenhouse has the following problems: (1) The air temperature and soil temperature inside the greenhouse are too low in the daytime and at night to reach the optimal environmental temperature for plant growth; (2) based 
on the principle of the greenhouse effect, the air temperature in the greenhouse fluctuates too much in the daytime to realize flexible control; (3) the soil temperature is always too low; and (4) indoor air temperature and soil temperature changes are not synchronous and harmonious, resulting in plant growth stagnation, rotten roots, or even no roots [2].

To solve the above problems, setting an active artificial heating system in the greenhouse can improve the thermal environment and promote plant growth [3]. Many researchers at home and abroad have carried out research work on the heating system of the greenhouse, mainly including the optimization of heating heat sources and heating methods. Several representative research examples are as follows.

In terms of heat source selection, the use of traditional fossil energy (such as coal, natural gas, etc.) for greenhouse heating is facing a huge challenge, because of the high cost and low environmental benefits, it is gradually being phased out and replaced by renewable energy sources such as solar energy, geothermal energy, and biomass energy [4]. Active heating of greenhouses with solar energy as the heat source is accepted by many people. For example, Joudi et al. [5] put six solar air collector plates $(2.3 \mathrm{~m} \times 0.6 \mathrm{~m})$ on the top of a single slope glass greenhouse $\left(7.6 \mathrm{~m}^{2}\right)$, which can directly provide heating air for the greenhouse during the day and can store a certain amount of heat to heat the greenhouse at night. The results show that when the collector covers $45 \%$ of the roof area, the solar collector can meet the heating demand of the greenhouse. However, due to the unstable performance of active solar heating systems, it is often used in conjunction with energy storage systems, such as water storage systems [6,7], rock bed energy storage systems [8-10], and PCM storage energy system [11,12]. Some scholars even apply photovoltaic power generation systems to greenhouse heating $[13,14]$. These coupling systems can effectively enhance the heating stability of solar heating systems to a certain extent, but they also undoubtedly increase the investment costs of solar heating systems and increase the difficulty of maintenance management. The reality that solar heating systems are constrained by geographical and climatic conditions will not change.

Geothermal energy has better performance stability than solar energy, and it often appears in the form of ground source heat pumps in greenhouse heating [15-17]. Although the ground source heat pump system has good environmental benefits and lower operating costs, the high investment cost is the main reason for limiting its promotion and application. Nemś et al. [18] analyzed the economics of ground source heat pump system for greenhouse heating in Polish climate, and the results show that compared with coal-fired boiler heating system, the operating cost of ground source heat pump system is saved $62 \%$, but the investment cost is more than 3.5 times higher, and the total investment payback period is up to 18 years. Chai et al. [19] made a systematic evaluation of the economic and environmental benefits of using a ground source heat pump system as a heating system in a greenhouse in northern China (Beijing area) through experiments. The results show that, compared with traditional coal-fired heating systems, its carbon dioxide emissions have been reduced by $41.9 \%$. However, the application of geothermal energy requires greater upfront capital investment, a longer payback period, and requires professional operation and maintenance. It is not suitable for small and medium-sized commercial greenhouses and economically underdeveloped rural areas in China.

In comparison, although the biomass heating system will sacrifice some environmental benefits, it has obvious advantages in performance stability and investment cost. Chau et al. [20] conducted an economic analysis of a 7.5-hectare greenhouse heated by biomass boilers in Colombia. The net present value (NPV) shows that it is more economical to install a biomass boiler to provide $40 \%$ of the annual heat demand than to use a natural gas boiler to provide all the heat. Zhang et al. [21] used a burning-cave to heat a solar greenhouse in northern China. The experiment shows that the heating effect of the heating system is obvious, which is $3-8^{\circ} \mathrm{C}$ higher than that of the solar greenhouse without heating facilities. The present value and annual value of the cost are $58.71 \mathrm{RMB} / \mathrm{m}^{2}$ and $9.56 \mathrm{RMB} / \mathrm{m}^{2}$, respectively, which are lower than that of the hot air heating system, hot water heating system, and electric heating system. As a whole, the application of biomass energy in the greenhouse heating system has a bright future, which meets the requirements of stability and economy of the greenhouse 
heating system. As a largely agricultural country, China has abundant biomass resources and a large greenhouse heating application market. However, the existing research on biomass heating is still slightly insufficient, and more relevant research work is needed.

In addition to optimizing the heat source, the heating method also plays an important role in maintaining the indoor thermal environment of a greenhouse. According to the different heating objects, it can be divided into two ways: Heating indoor air and heating soil. In the early research of the greenhouse heating system, there was a lack of understanding of the essential needs of the plant growth environment. It was considered that the air temperature in the greenhouse was the key to plant growth. Therefore, the early research work focused on the heating of indoor air, such as hot air heating, radiator heating, and infrared radiation heating. With the deepening of research and the test of practice, such a heating method with air temperature as the only measurement standard ignores the positive effect of soil temperature on crop growth, which is not conducive to crop growth, will cause the phenomenon of no root and rotten root, and will also cause a lot of waste of energy. Therefore, the research of the soil heating system in greenhouses has been paid more and more attention. Zhang et al. [21] experimentally studied the influence of the burning-cave hot water soil heating system on the heating effect of solar greenhouse in winter. The result shows that the buried hot water pipes could raise the soil temperature $20 \mathrm{~cm}$ deep to $20-23{ }^{\circ} \mathrm{C}$. It is $5{ }^{\circ} \mathrm{C}$ higher than the soil temperature of the unheated greenhouse, and the energy-saving rate of the whole heating system is $46.14 \%$. However, the system needs specific conditions, so it is difficult to be widely used.

Based on the research and summary of the existing greenhouse heating system, the author believes that the traditional fossil energy heating system will be phased out due to the characteristics of serious pollution and a weak economy, and the application of renewable energy such as solar energy, geothermal energy, and biomass energy will be gradually deepened, focusing on the development of high energy efficiency, simplicity, stability, and economic optimization. Considered comprehensively, it is believed that biomass energy has greater application potential in the current era and policy background of rural environmental governance and Rural Revitalization Strategy in China. Therefore, the authors carried out a new type of experimental research on the greenhouse heating system with biomass as primary energy input, aiming to improve the indoor thermal environment of rural greenhouse and promote the development of the rural economy. The outstanding features of the system are as follows: (1) The abundant biomass resources (agricultural and forestry waste) in rural areas are used as primary energy input; (2) the heating system uses flue gas instead of water as working fluid, without storage system, and has the ability of rapid heating, which is more suitable for intermittent heating; (3) taking the soil as a heat transfer carrier to achieve synchronous and balanced changes in soil and air temperature; and (4) the polyethylene pipe (PE) with acid and alkali resistance is used as heat network, which has a long service life. Through experimental research and economic analysis, the results are expected to provide new ideas and research directions for greenhouse heating in rural areas of China and promote the sustainable development of rural agriculture.

\section{The Framework of Biomass Heating System in Greenhouses}

The biomass heating system is mainly composed of four parts: Flue gas generator, flue gas treatment device, heat exchanger, and flue gas transmission device (Figure 1). The system uses biomass flue gas as a thermal working medium and heats the surface soil inside the greenhouse through the flue gas-soil heat exchanger, thereby regulating the indoor thermal environment of the entire greenhouse. The system flowchart is shown in Figure 2. 


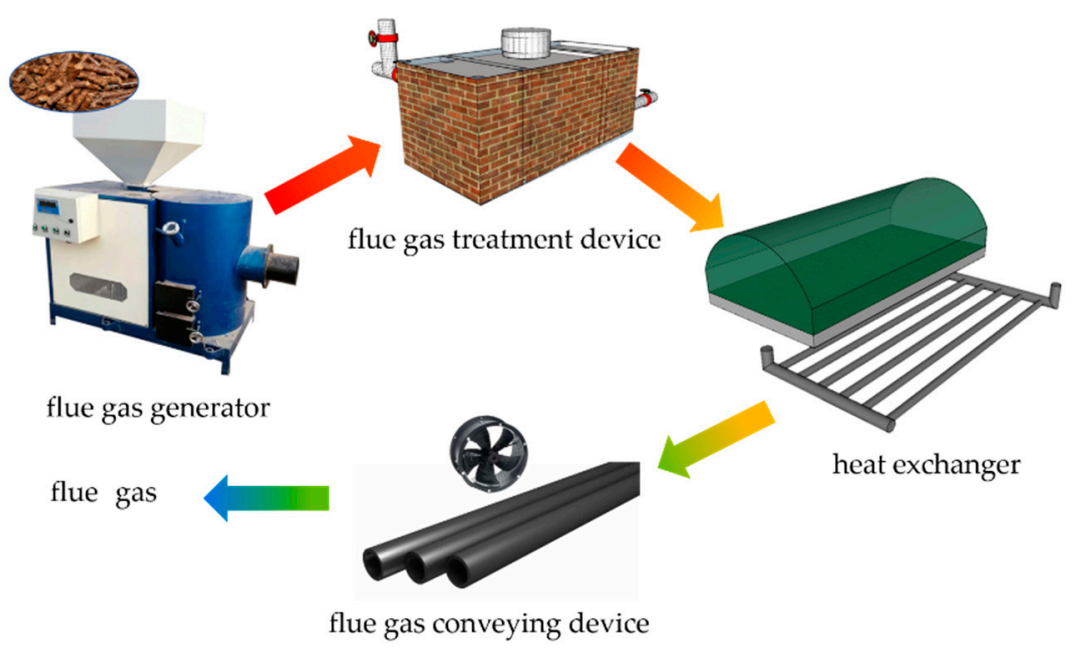

Figure 1. Schematic diagram of biomass heating system in greenhouses.

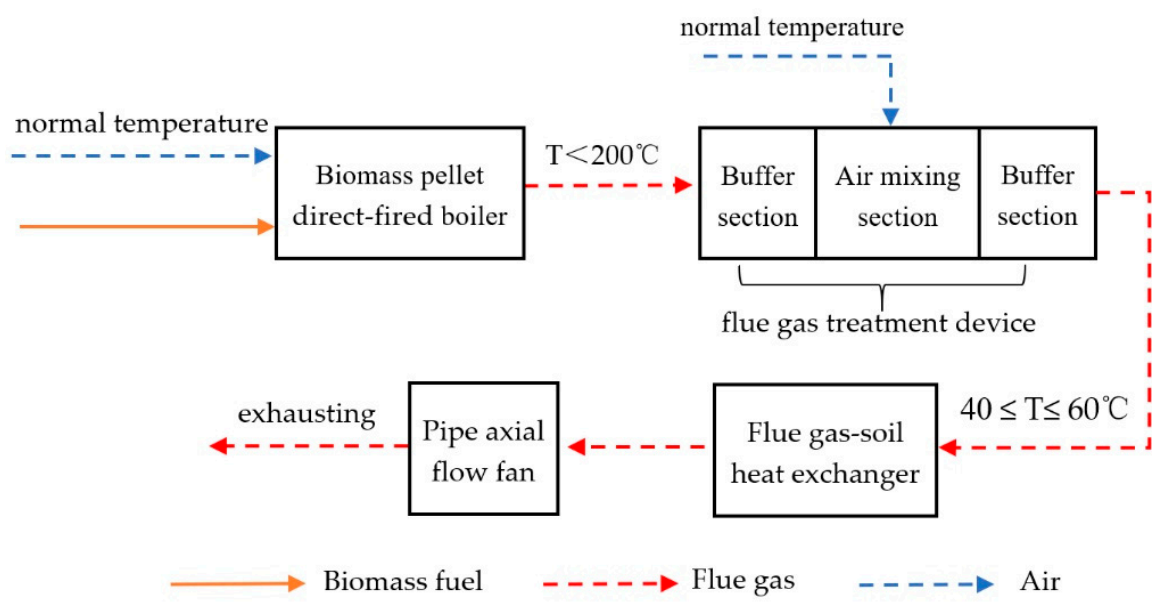

Figure 2. Flowchart of greenhouse biomass heating system.

The flue gas generator, a biomass pellet direct-fired boiler, is where the biomass fuel (biomass particles or tubers) is burned. Then, the generated high-temperature flue gas is mixed with air in the flue gas mixing section in the boiler, and the low-temperature flue gas, not higher than $200{ }^{\circ} \mathrm{C}$, is prepared by regulating the airflow. Finally, the low-temperature flue gas is sent to the flue gas treatment device.

The flue gas treatment device is composed of three parts, named buffer section, air mixing section, and buffer section. Firstly, the buffer section is equipped with a filter screen to filter the ash and solid particles in the low-temperature flue gas roughly; secondly, the flue gas in the air mixing section is fully mixed with the air to further reduce the flue gas temperature to $40-60^{\circ} \mathrm{C}$; finally, the flue gas is nearly evenly mixed through the buffer section as the low-temperature heat source output by the heat exchanger.

The flue gas-soil heat exchanger, which is the buried heat exchange pipe network, realizes the heat exchange between the flue gas and the shallow soil inside the greenhouse. The pipe network is composed of high-density polyethylene pipes (PE) connected in parallel and buried under the soil $(40-80 \mathrm{~cm})$ in the greenhouse.

The flue gas conveying device is composed of two parts: A power device and a transport pipeline. The power device is a pipeline axial-flow fan, which is installed at the end of the flue gas exhaust pipe to provide stable power for the gas transmission; the transmission pipe is composed of PE pipe. 


\section{Materials and Methods}

\subsection{The Experimental Greenhouse}

The experimental greenhouse (Figure 3) is located in Yuhu District, Xiangtan City, Hunan Province $\left(\mathrm{N}: 27^{\circ} 55^{\prime} ; \mathrm{E}: 112^{\circ} 5^{\prime}\right)$. It is a traditional plastic film greenhouse with a light steel structure (covered with felt at night as insulation quilt). The length of a single greenhouse is $22.0 \mathrm{~m}$ in the North-South longitudinal direction, $8.0 \mathrm{~m}$ in the East-West span, $3.1 \mathrm{~m}$ in the ridge height, and $1.1 \mathrm{~m}$ in the minimum height. No crops were planted in the greenhouse during the experiment.
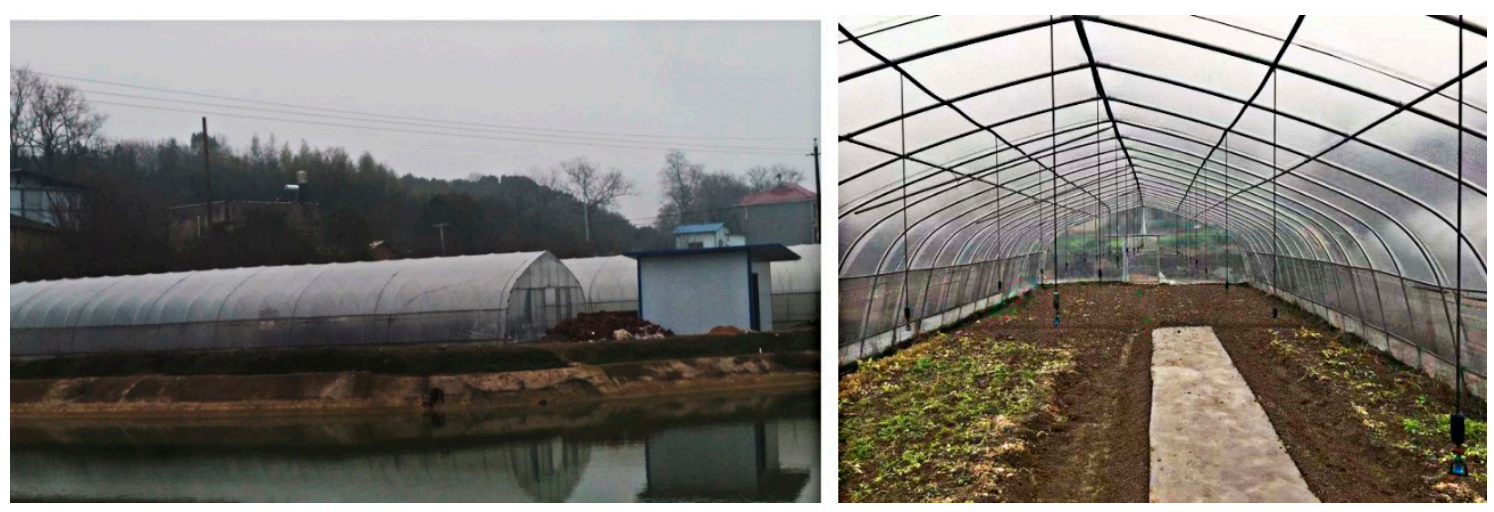

Figure 3. The overall appearance (left) and internal layout (right) of the experimental greenhouse.

\subsection{The Biomass Heating System Layout}

The experiment was a control group experiment. The experimental greenhouse was divided by plastic film in the middle along the North-South length direction to form two greenhouses of the same size, which were used as the heated greenhouse and the traditional unheated greenhouse, respectively. The whole set of biomass heating system was installed in the heated greenhouse. The traditional unheated greenhouse was the same as the heating greenhouse except that there was no heating system.

The buried heat exchange pipe network (Figure 4) was composed of 17 pipes (De63) with $10 \mathrm{~m}$ long in parallel. The buried heat exchange pipe network was laid along the lengthways of the greenhouse, with a depth of $50 \mathrm{~cm}$, a spacing of $40 \mathrm{~cm}$, and 3-cm-thick perlite was laid below as the insulation layer. At the same time, a regulating valve was installed on each buried heat pipe to control the volume flow of flue gas, and the exposed pipe was treated with thermal insulation materials.
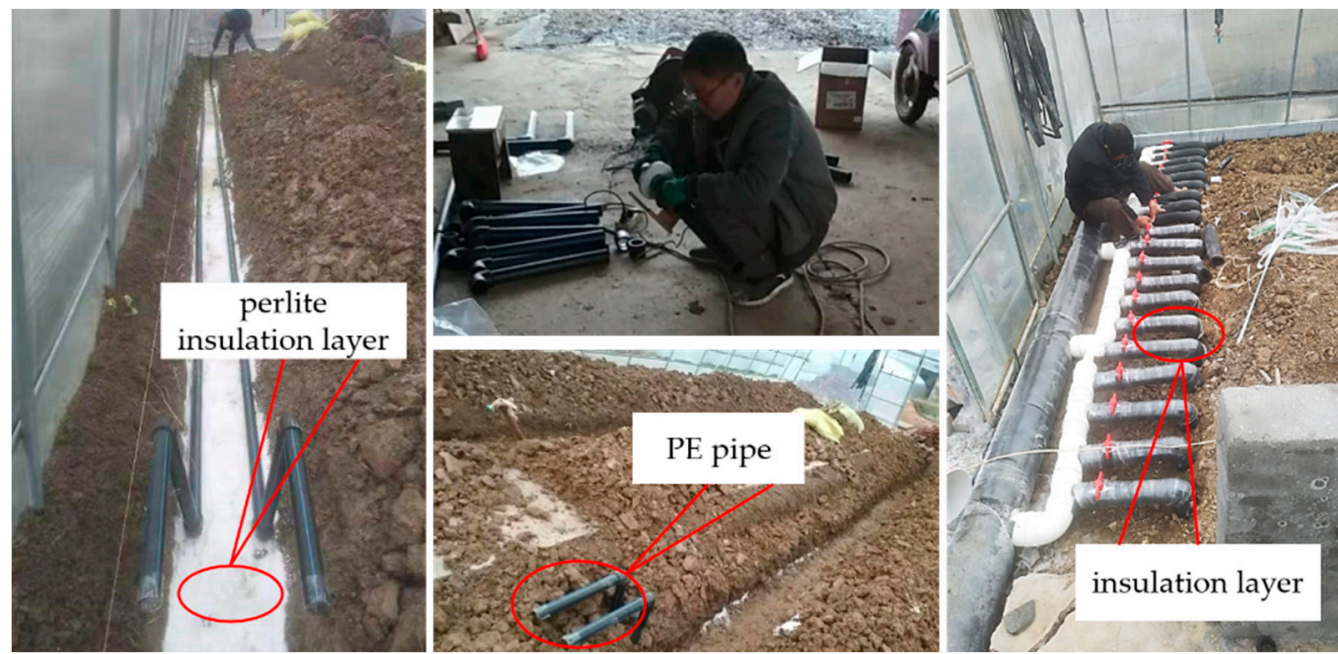

Figure 4. Buried heat exchange pipe network. 
The biomass boiler, which was a direct-fired biomass boiler, which can burn biomass particles, small stem stalks, and firewood. In this experiment, corncob biomass tuber was used as fuel, and the fuel quantity of the boiler was $2-5 \mathrm{~kg} / \mathrm{h}$. The boiler room of this experiment was on the side of the greenhouse, and its boiler and boiler room are shown in Figure 5.
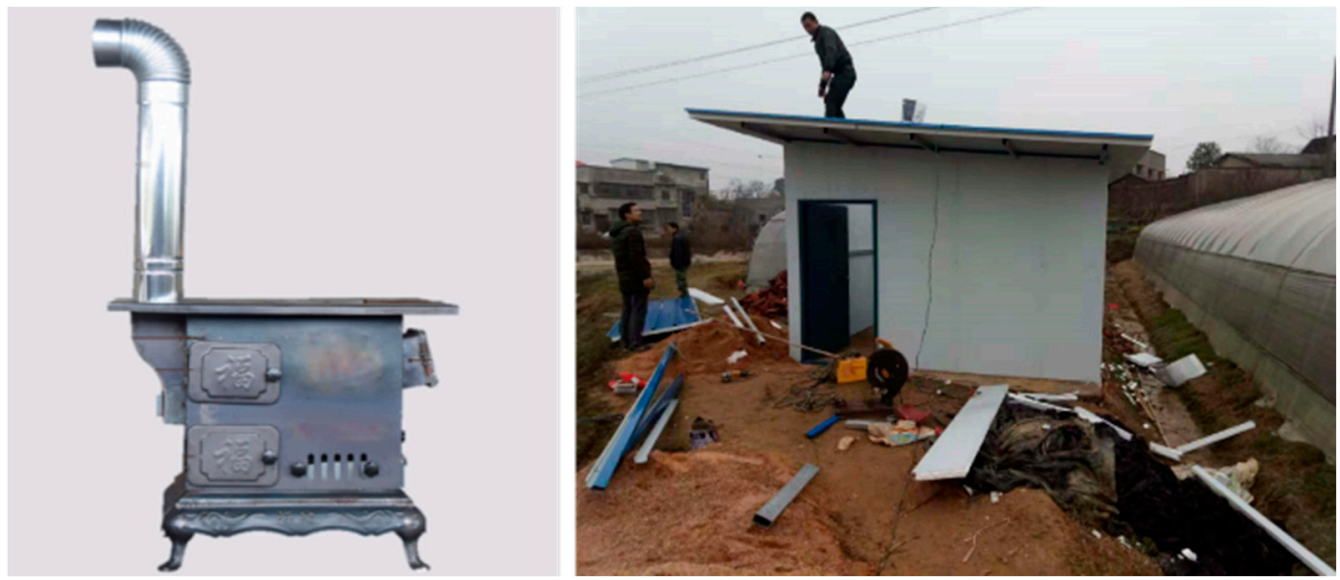

Figure 5. Biomass boiler (left) and biomass boiler room (right).

\subsection{Experimental Testing and Measuring Point Distribution.}

\subsubsection{Experimental Testing Instrument}

In this experiment, the handheld intelligent agricultural meteorological environment monitor HM-QX13 produced by Shandong Hengmei Electronic Technology Co., LTD was used. According to different situations, the temperature, wind speed, $\mathrm{CO}_{2}$ concentration, and other parameters can be quickly measured by changing different measuring probes, and the data can be displayed in real-time through the display screen and stored in the internal chip of the speedometer. After the measurement, the data in the recorder can be downloaded to the computer through the attached software, which is convenient for saving and data analysis. The instrument was composed of a speedometer, sensors, UBS data lines, a portable suitcase, and other parts (Figure 6).
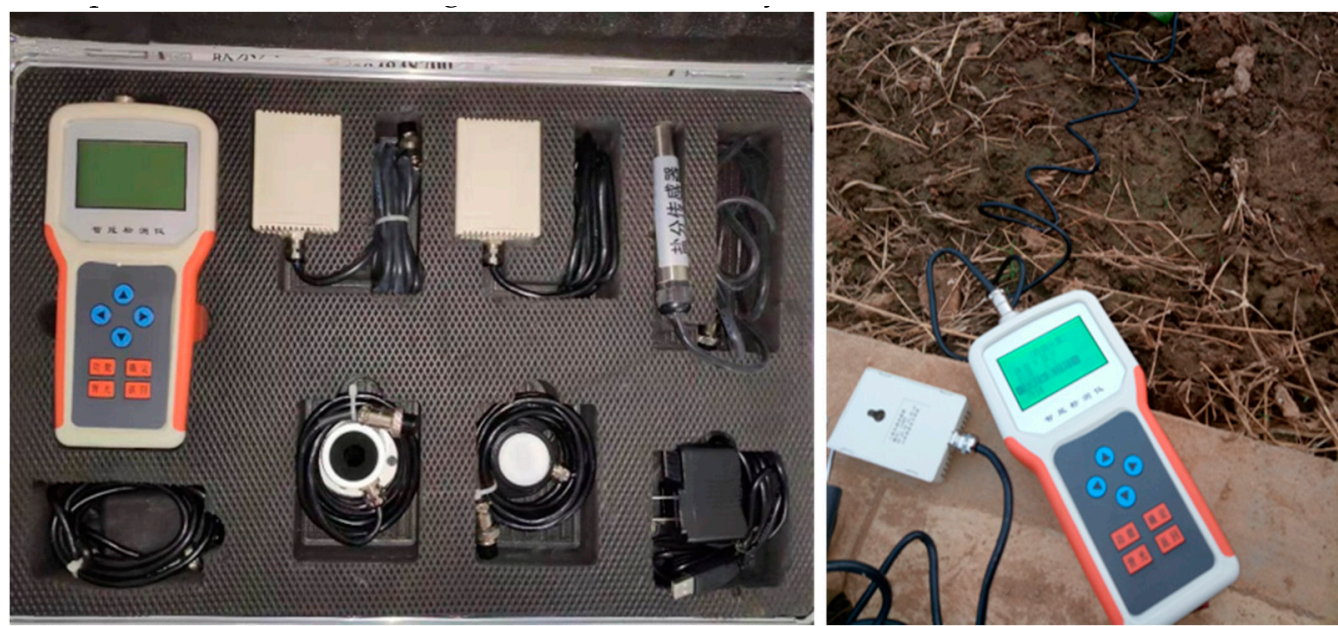

Figure 6. Hand-held intelligent agro-meteorological environment monitor (left) and testing (right).

In this experiment, the instrument was used to measure soil temperature, air temperature, and ambient wind speed. The relevant technical parameters of the instrument are as follows. 
Tester size: $176 \mathrm{~mm} \times 90 \mathrm{~mm} \times 40 \mathrm{~mm}$;

LCD screen: $50 \mathrm{~mm} \times 65 \mathrm{~mm}$;

Air temperature measurement range: $-30-70{ }^{\circ} \mathrm{C}$, accuracy: $\pm 0.2{ }^{\circ} \mathrm{C}$, resolution: $0.01{ }^{\circ} \mathrm{C}$;

Soil temperature measurement range: $-40-120{ }^{\circ} \mathrm{C}$, accuracy: $\pm 0.2{ }^{\circ} \mathrm{C}$, resolution: $0.01^{\circ} \mathrm{C}$;

Wind speed measurement range: $0-30 \mathrm{~m} / \mathrm{s}$, accuracy: $\pm 0.5 \%$, resolution: $0.1 \mathrm{~m} / \mathrm{s}$.

\subsubsection{Testing Points}

To objectively and accurately describe the changes of indoor thermal environment caused by the heating system, the same testing points were set in both heated and unheated greenhouses, including the testing points of soil surface temperature, indoor air temperature, outdoor air temperature, and wind speed, as shown in Figure 7.

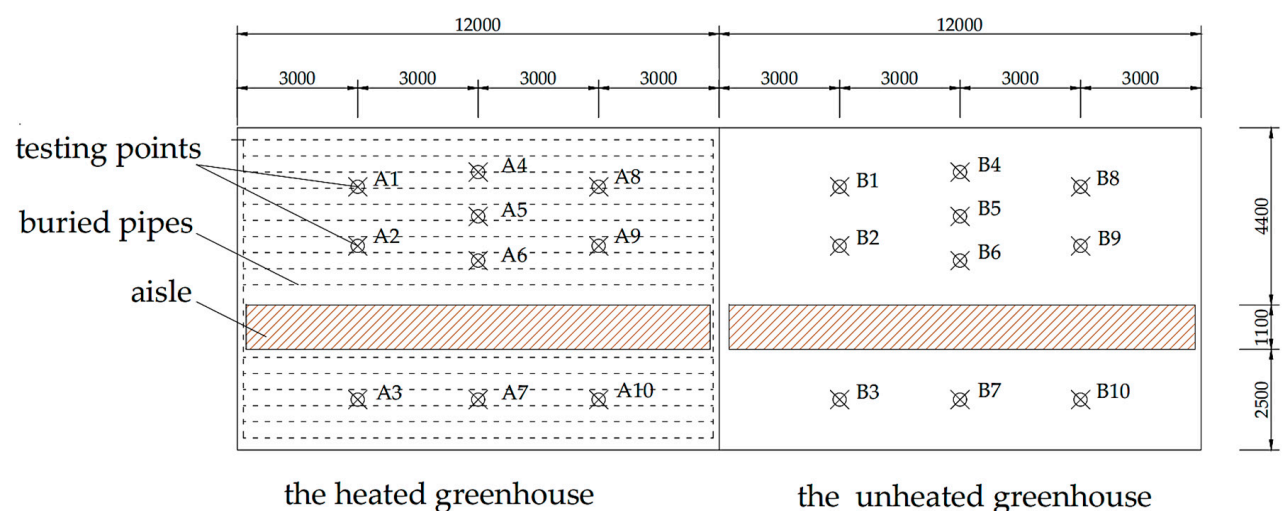

a

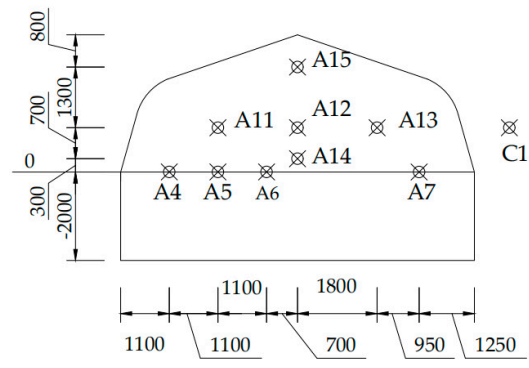

the heated greenhouse

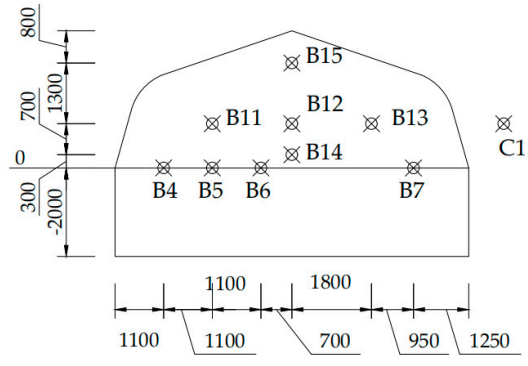

the unheated greenhouse

b

Figure 7. Schematic representation of measuring points in the experimental greenhouse (unit: $\mathrm{mm}$ ).

(a) top view; (b) side view.

Figure 7a shows locations of different soil surface temperature measuring points inside the experimental greenhouse, with a total of 20 measuring points (A1-A10, B1-B10).

The air temperature measurement points were located at the centerline of a single greenhouse (that is, $1 / 4$ and 3/4 along the north-south longitudinal direction of the greenhouse in Figure 7a. And as shown in Figure $7 \mathrm{~b}$, at the height of $0.3 \mathrm{~m}, 1 \mathrm{~m}$, and $2.3 \mathrm{~m}$ above the ground, there were 1, 3, and 1 air temperature measuring points, respectively. Therefore, there were 5 measuring points (A11-A15) in a single small greenhouse and 10 measuring points in two greenhouses.

A measuring point $(\mathrm{C} 1$ ) was located outside the greenhouse (Figure $7 \mathrm{~b}$ ), which can measure the ambient temperature and wind speed. 


\subsubsection{Testing Method}

In this experiment, the HM-QX13 hand-held measuring instrument was used to monitor the changes of soil surface temperature, indoor air temperature, outdoor air temperature, and wind speed at each measuring point during the experiment. The experimental data were recorded and processed manually once an hour.

\section{Results}

The experiment was carried out from December 10, 2019, to January 10, 2020 (discontinuous heating experiment), and the night measurement data of December 18, 2019, were used for analysis. The experimental condition was that the average temperature of flue gas was $50{ }^{\circ} \mathrm{C}$, and the average velocity of flue gas flow in the buried pipe was $3.0 \mathrm{~m} / \mathrm{s}$. In this paper, the software origin $2018 \mathrm{~b}$ was used for data processing and drawing.

\subsection{Heating Performance Analysis of Heating System}

The experimental data of stable operation of the heating system from the night of December 18 to the early morning of the next day (18:00-7:00 a.m. of the next day) were recorded. Taking the temperature data of measuring points (A1-A10) to calculate the average value to get the indoor soil surface temperature of the heated greenhouse, taking the temperature data of measuring points (B1-B10) to calculate the average value to get the indoor air temperature of the unheated greenhouse; take the temperature data of measuring points (A11-A15) to calculate the average value to get the indoor air temperature of the heating greenhouse, and taking the temperature data of measuring points (B11-B15) to calculate the average value to get the indoor air temperature of the non-heating greenhouse.

It can be seen from Figure 8 that the indoor soil surface temperature and air temperature of the heated plastic greenhouse were significantly higher than those of the unheated plastic greenhouse, indicating that the biomass heating system of the plastic greenhouse is effective. Comparison data show that the average indoor air temperature of the plastic greenhouse with heating was $12.2{ }^{\circ} \mathrm{C}$, which was $5.1{ }^{\circ} \mathrm{C}$ higher than that of the plastic greenhouse without heating; the change range of indoor temperature in the heated greenhouse was slightly smaller than that in the unheated greenhouse, indicating that the heated greenhouse has stronger resistance to ambient temperature change. The changing trend of soil temperature and air temperature was the same in the greenhouse, which was to decrease first and then increase, and the lowest temperature appears around 4:00 to 6:00 in the morning.

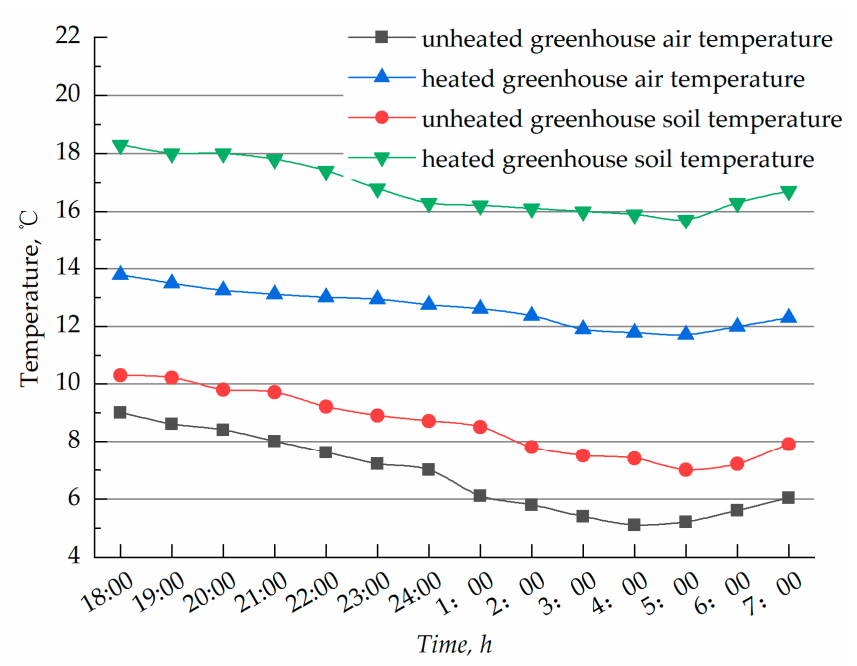

Figure 8. Comparison of soil temperature and air temperature between the heated greenhouse and the unheated greenhouse. 
Figure 9 shows that the indoor air temperature change trend of the heated greenhouse was consistent with the external environment temperature change trend, but the change range was smaller than the external environment change range; the indoor average temperature was higher than the ambient temperature $8.4{ }^{\circ} \mathrm{C}$, and the lowest temperature appeared at 5:00 is $11.7^{\circ} \mathrm{C}$.

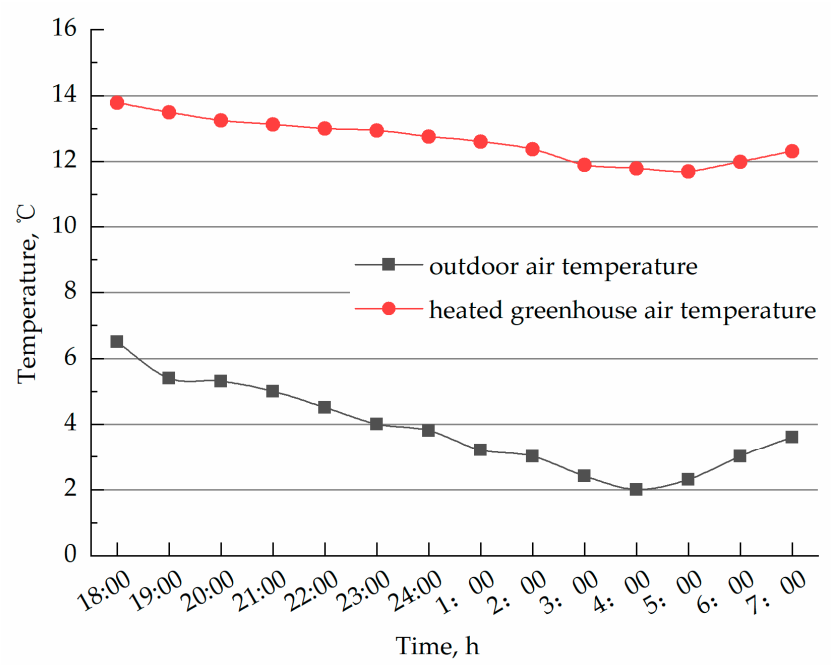

Figure 9. Comparison of indoor air temperature and outdoor air temperature of the plastic heated greenhouse.

\subsection{Changing Regularity of Soil Temperature in Width}

The temperature data of A4, A5, A6, and A7 were collected to study the lateral temperature change of soil on the surface of the greenhouse. As shown in Figure 10, the changing trend of the soil temperature at each measuring point was the same. With the advance of time, the soil temperature showed the change rule of first decreasing and then rising. The lowest temperature point appeared around 5:00-6:00 in the morning, which was mainly caused by the change of external environment. For the four measuring points (A4-A7), the temperature at A5 and A6 was high, while that at A4 and A7 was low, which is caused by the different positions of soil measuring points in the greenhouse. In comparison, A4 and A7 were closer to the outside of the greenhouse, which are greatly affected by the external environment. At the same time, a large amount of heat will permeate into the soil outside the greenhouse boundary. Therefore, it is necessary to properly conduct heat preservation treatment for the soil around the greenhouse, such as setting a cold-proof ditch.

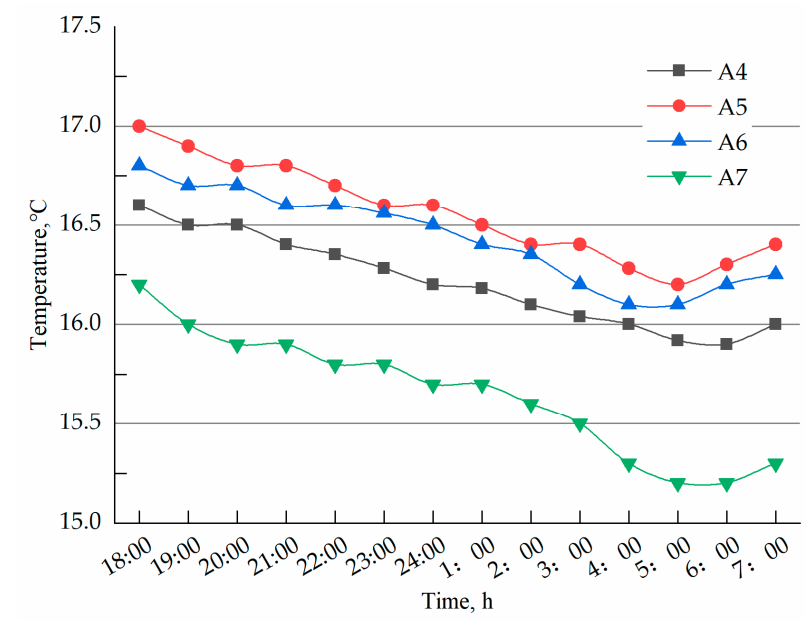

Figure 10. Changing regularity of soil temperature in width. 


\subsection{Changing Regularity of Soil Temperature in Length}

The temperature data of $\mathrm{A} 3, \mathrm{~A} 7$, and $\mathrm{A} 10$ were taken to study the temperature change of the surface soil along the direction of the buried pipeline laying in the heated greenhouse. Figure 11 shows that along the laying direction of the buried pipeline, the surface soil temperature showed a decreasing change law. The reason for this phenomenon is that along the direction of flue gas flow, the flue gas temperature gradually decreased, resulting in the decrease of the heat exchange temperature difference between the soil and flue gas, which was finally reflected in the decrease of the soil surface temperature. According to the data in the figure, the average temperature difference between $\mathrm{A} 3$ and $\mathrm{A} 10$ was $1.1^{\circ} \mathrm{C}$. In the actual greenhouse planting process, this phenomenon should be avoided as much as possible to prevent the occurrence of uneven plant growth and affect the quality of agricultural products. In actual projects, the unevenness of soil temperature distribution can be reduced by increasing the flue gas flow rate, inclined buried pipes, or crossed buried pipes.

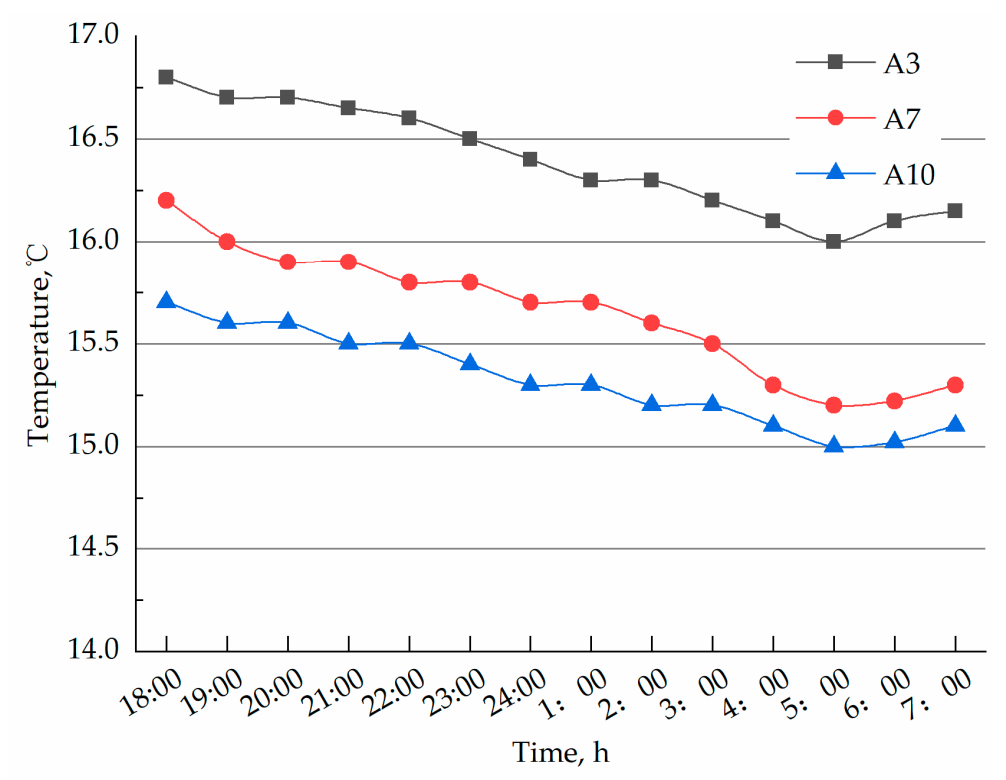

Figure 11. Changing regularity of soil temperature in length.

\subsection{Changing Regularity of Air Temperature in the Horizontal Direction}

Taking the experimental data of measuring points A11, A12, and A13, we were able to analyze the air temperature variation law in the horizontal direction of the greenhouse. In Figure 12, the indoor air temperature was greatly affected by the change of the outdoor air temperature, and the decrease of the indoor air temperature reached about $2.0^{\circ} \mathrm{C}$. In the horizontal space, the temperature change trends of the three measurement points were the same, but it can be seen from the figure that the temperature of the A12 measuring point was higher than the temperature of the A11 and A13 measuring points, and the temperature values of the A11 and A13 measuring points were similar. The reason for this phenomenon is that the two measuring points A11 and A13 are closer to the outside of the greenhouse and are more affected by the external environment. Therefore, the greenhouse can be covered with heat insulation at night to reduce this effect. However, overall, the indoor air temperature distribution was acceptable, and the maximum average temperature difference between the three measurement points was $0.36^{\circ} \mathrm{C}$. 


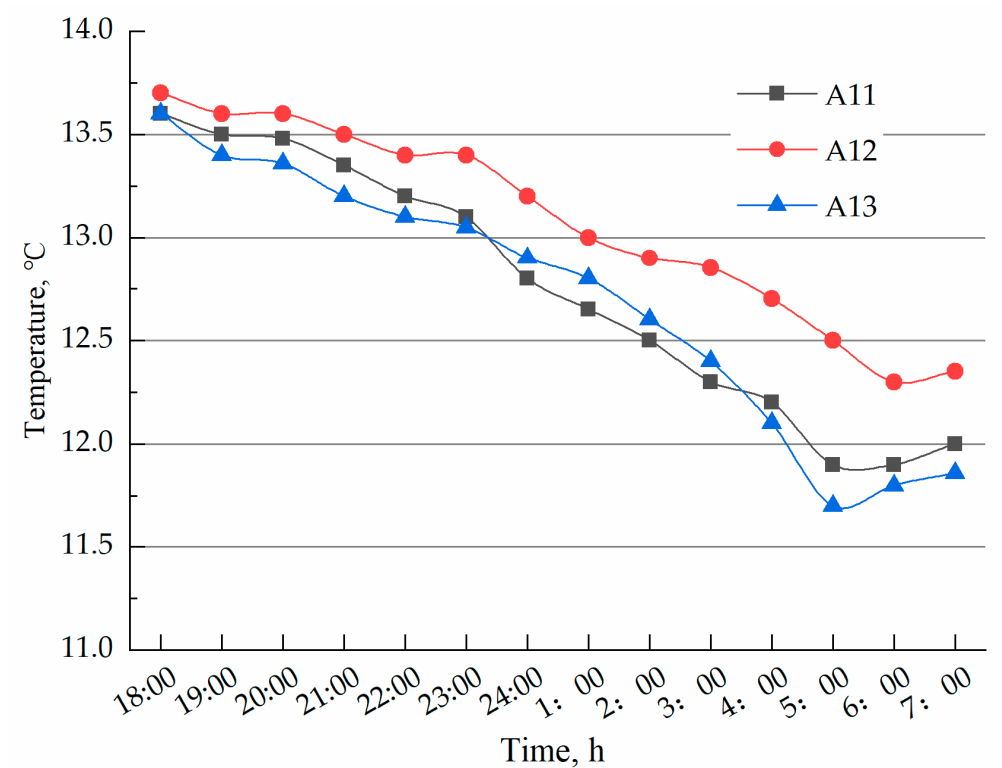

Figure 12. Changing regularity of air temperature in the horizontal direction.

\subsection{Changing Regularity of Air Temperature in the Vertical Direction}

Taking the temperature experimental data of measuring points A12, A14, and A15, we were able to analyze the changing law of air temperature in the vertical direction. According to Figure 13 and the distribution map of measuring points, the indoor air temperature in the heating greenhouse gradually decreased from the soil surface to the plant canopy to the top of the greenhouse. The average air temperature of greenhouse bottom ( $0.3 \mathrm{~m}$ above ground), plant canopy ( $1.0 \mathrm{~m}$ above ground), and greenhouse top $\left(2.3 \mathrm{~m}\right.$ above ground) were $13.4{ }^{\circ} \mathrm{C}, 13.1{ }^{\circ} \mathrm{C}$, and $11.4{ }^{\circ} \mathrm{C}$, respectively. And the maximum air temperature difference between the bottom and top of the greenhouse was $2.0^{\circ} \mathrm{C}$.

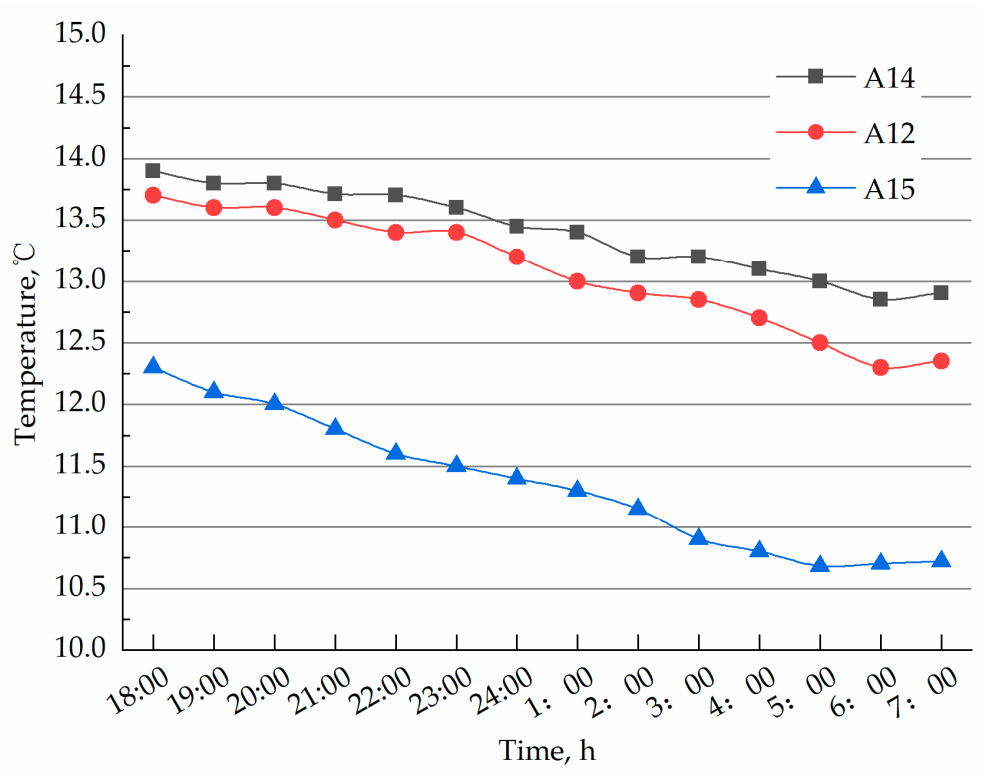

Figure 13. Changing regularity of air temperature in the vertical direction.

More than $70 \%$ of the heat loss of greenhouses comes from the heat transfer of temperature difference through the ceiling. Properly reducing the indoor air temperature, and the indoor and outdoor temperature differences can reduce the energy consumption of greenhouses. Therefore, the indoor temperature distribution of the experimental heating greenhouse can not only ensure the 
demand of plant growth on the environment temperature, but also reduce the heat loss caused by the temperature difference inside and outside the plastic greenhouse to a certain extent, which is an important way to achieve energy conservation and consumption reduction of the plastic greenhouse.

\section{Heating System Performance Evaluation}

\subsection{Evaluation of Indoor Thermal Environment}

Temperature is one of the most important influencing factors for plant growth. The basic task of greenhouse heating is to make the indoor temperature meet the needs of plant growth. Therefore, the temperature is used as the evaluation index of the effect of the greenhouse heating system, including indoor air temperature and indoor surface soil temperature. Table 1 lists the temperature requirements of some common vegetables and melons in winter, which can be used as reference indicators for the evaluation of the thermal environment of plastic greenhouses.

Table 1. The optimum temperature of greenhouse vegetables and fruits (unit: ${ }^{\circ} \mathrm{C}$ ).

\begin{tabular}{cccccccc}
\hline & \multicolumn{2}{c}{ Daytime Temperatures } & \multicolumn{2}{c}{ Night Temperatures } & \multicolumn{2}{c}{ Soil Temperatures (100 mm) } \\
\cline { 2 - 7 } & Highest & Acceptable & Acceptable & Lowest & Highest & Acceptable & Lowest \\
\hline Tomatoes & 35 & $20-25$ & $8-13$ & 5 & 25 & $15-18$ & 13 \\
Aubergine & 35 & $23-28$ & $13-18$ & 10 & 25 & $18-20$ & 13 \\
Pepper & 35 & $25-30$ & $15-20$ & 12 & 25 & $18-20$ & 13 \\
Cucumber & 35 & $23-28$ & $10-15$ & 8 & 25 & $18-20$ & 13 \\
Watermelon & 35 & $23-28$ & $13-18$ & 10 & 25 & $18-20$ & 13 \\
Muskmelon & 35 & $25-30$ & $18-23$ & 15 & 25 & $18-20$ & 13 \\
\hline
\end{tabular}

In this study, the purpose of improving the indoor thermal environment of plastic greenhouses was achieved by heating the soil. The indoor air temperature formed a distribution trend that gradually decreased from bottom to top. In this study, the actual soil surface temperature at night was $16.8^{\circ} \mathrm{C}$, and the average air temperature was $12.2^{\circ} \mathrm{C}$.

Due to the limitation of experimental conditions, the actual soil temperature measured in this experiment is the surface soil temperature. Taking the actual measured temperature of the soil + (1.0-1.5) ${ }^{\circ} \mathrm{C}$ as the $100 \mathrm{~mm}$ deep soil temperature, the average temperature of the $100 \mathrm{~mm}$ deep soil during the night heating stage of the plastic greenhouse is $17.8-18.3{ }^{\circ} \mathrm{C}$, which absolutely meets the minimum soil temperature requirements for common fruits and vegetables at night, and it can basically meet the requirement of the suitable soil temperature at night. At the same time, when the soil temperature is suitable, the temperature of the air in the greenhouse can be appropriately reduced to reduce the heat load in winter, which is a manifestation of energy saving.

\subsection{Thermal Efficiency Evaluation}

Thermal efficiency is defined as the ratio of the effective utilization heat to the total input heat, and the expression is shown in formula (1)

$$
\eta=\frac{Q_{\mathrm{e}}}{Q} \times 100 \%
$$

where $Q_{\mathrm{e}}$ is the effective utilization heat $(\mathrm{W})$, the energy provided by the heat exchanger to the greenhouse in a stable state, that is, the heat load of the plastic greenhouse at night (including heat transfer loss $\left(q_{1}\right)$ and penetration heat loss $\left(q_{1}\right)$ through the film) [22]; $Q$ is the total input energy (unit: W), which is calculated by the low calorific value of corn cob fuel in this study.

$$
Q_{\mathrm{e}}=q_{1}+q_{2}=\mu A\left(t_{\mathrm{i}}-t_{\mathrm{o}}\right)+0.5 k V N\left(t_{\mathrm{i}}-t_{\mathrm{o}}\right)
$$


where $\mu$ is the heat transfer coefficient of the greenhouse ceiling $\left(\mathrm{W} /\left(\mathrm{m}^{2} \cdot \mathrm{K}\right)\right), \mu=3.75 \mathrm{~W} /\left(\mathrm{m}^{2} \cdot \mathrm{K}\right) ; A$ is the ceiling area of plastic greenhouse $\left(\mathrm{m}^{2}\right), A=151.2 \mathrm{~m}^{2} ; t_{\mathrm{i}}$ is the indoor temperature $\left({ }^{\circ} \mathrm{C}\right)$ of the plastic greenhouse, that is, the average indoor temperature at night during the heating period, $t_{\mathrm{i}}=12.2^{\circ} \mathrm{C}$; $t_{0}$ is the outdoor air temperature $\left({ }^{\circ} \mathrm{C}\right)$, that is, the average outdoor temperature at night during the experiment, $t_{\mathrm{o}}=3.9^{\circ} \mathrm{C} ; k$ is wind speed factor, $k=1 ; V$ is the volume of the plastic greenhouse $\left(\mathrm{m}^{3}\right)$, $V=162 \mathrm{~m}^{3} ; N$ is the ventilation times of plastic greenhouse, $N=1$.

It is calculated that the effective use of heat for heating is $Q_{e}=5378.4 \mathrm{~W}$. During the period of stable heating, the actual amount of fuel used was $2.4 \mathrm{~kg} / \mathrm{h}$ on average, and the low calorific value of the corn cob is $17,730 \mathrm{~kJ} / \mathrm{kg}$. Therefore, the thermal efficiency of the heating system is $45.5 \%$.

\subsection{Economic Analysis}

In addition to ensuring normal agricultural production, the basic task of the active greenhouse heating system is to obtain excess income. Therefore, it is of great practical significance to evaluate the advantages and disadvantages of the heating system with economic benefit indicators. In this study, the economic evaluation of the system is carried out by calculating the investment payback period.

\subsubsection{Biomass Heating System Investment Cost}

The initial investment of the biomass heating system mainly includes labor cost, material cost, and equipment cost.

The cost list is shown in Table 2. Therefore, the investment cost for the construction of a biomass heating system in a plastic greenhouse per unit area is $91.7 \mathrm{yuan} / \mathrm{m}^{2}$.

Table 2. Investment cost list of biomass heating system.

\begin{tabular}{cccccc}
\hline No. & \multicolumn{2}{c}{ Items } & Quantity & Yuan per Unit & Value (Yuan) \\
\hline 1 & Labor cost & Labor cost & 20 & 150.0 & 3000.0 \\
\hline 2 & & De63 PE pipe & 210 & 13.5 & 2835.0 \\
3 & & $90^{\circ}$ bend $^{1}$ & 10 & 5.0 & 50.0 \\
4 & \multirow{2}{*}{ Material cost } & Socket tee $^{1}$ & 36 & 3.2 & 115.2 \\
5 & Brick & 500 & 0.3 & 150.0 \\
6 & & Cement & 2 & 18.0 & 36.0 \\
7 & & Insulation quilt & 3 & 135.0 & 405.0 \\
8 & & Hand valve & 2 & 65.0 & 130.0 \\
\hline 9 & \multirow{2}{*}{ Facility cost } & Fan & 1 & 180.0 & 180.0 \\
10 & & boiler & 1 & 1900.0 & 1900.0 \\
\hline 11 & & Total & & 8801.2 \\
\hline
\end{tabular}

${ }^{1}$ Due to the difference between the experimental pipeline connection and the actual project, according to the actual project, the pipe components in the table are slightly adjusted.

\subsubsection{Operation Cost of Heated Greenhouse}

The operation cost of the biomass heating system mainly includes fuel cost, electricity cost, and management cost.

Xiangtan City, Hunan Province is located in central China, has four distinct seasons with long winter and summer and short spring and autumn. Greenhouse heating adopts intermittent heating in winter, generally from November 15 to March 15 of the next year. Taking the winter of 2019 as an example, heating should be considered when the ambient temperature is below $10^{\circ} \mathrm{C}$, for a total of about $2160 \mathrm{~h}$.

The amount of fuel is calculated at $2.4 \mathrm{~kg} / \mathrm{h}$, with a $20 \%$ safety margin added, and a total of $6220.8 \mathrm{~kg}$ of fuel is used during the heating period. The corncob is calculated based on the market price of 120 yuan/ton, then the total fuel cost for a heating period is 746.5 yuan, and the annual fuel cost per unit of the greenhouse area is 7.8 yuan $/ \mathrm{m}^{2}$. 
The power equipment mainly includes fans, whose power is $0.27 \mathrm{~kW}$, and the electricity fee is calculated at 0.56 yuan $/ \mathrm{kWh}$, then the annual electricity fee of a greenhouse is $3.4 \mathrm{yuan} / \mathrm{m}^{2}$.

The management cost refers to the cost of employing on-duty personnel during the heating period. Since the test greenhouse is not large scale, its management cost calculation is not representative, and the management cost is relatively small in the entire cost structure, which is ignored here.

Therefore, the total annual cost of the biomass heating system in the plastic greenhouse is 11.2 yuan $/ \mathrm{m}^{2}$.

\subsubsection{Income Comparison between Heated Greenhouses and Unheated Greenhouses}

Under the effect of the biomass heating system, the indoor thermal environment of the plastic greenhouse has been greatly improved, and crops with a higher economy can be planted. Through field research, the local unheated plastic greenhouse can only grow low-temperature crops in winter, such as celery, which cannot bring considerable benefits to farmers due to the constraints of production and price. In the plastic greenhouse with the biomass heating system, tomatoes, peppers, cucumbers, and other high-yield and high price economic crops can be planted.

It is assumed that during the cultivation of the greenhouse, different economic crops are grown, and the management costs are the same. Taking the cultivation of tomatoes as an example and comparing the income from planting celery (Table 3), the minimum excess income obtained each year is 26.4 yuan $/ \mathrm{m}^{2}$, and the excess return rate is $105 \%$.

Table 3. Income comparison of the plastic greenhouse with or without a heating system.

\begin{tabular}{ccc}
\hline Items & Celery & Tomatoes \\
\hline Yield per mu $\left(\mathrm{kg} / 666.7 \mathrm{~m}^{2}\right)$ & $1500-2000$ & $11,000-13,000$ \\
The unit price (yuan $/ \mathrm{kg})$ & 2.8 & 3.8 \\
Growth cycle (mouths) & $2-3$ & 10.0 \\
Number of cultivated stubble per year & 3.0 & 1.0 \\
Annual income per square meter (yuan $\left./ \mathrm{m}^{2}\right)$ & $18.9-25.2$ & $62.8-74.2$ \\
\hline
\end{tabular}

\subsubsection{Payback Period}

The cash flow statement of the biomass heating system is shown in Table 4. Considering the loan interest rate of $10 \%$, the maximum investment recovery period is about 2.1 years, which has a good investment value.

Table 4. Statement of investment cash flow.

\begin{tabular}{ccccc}
\hline $\begin{array}{c}\text { Year Serial } \\
\text { Number }\end{array}$ & $\begin{array}{c}\text { Present Value } \\
\text { Coefficient }\end{array}$ & $\begin{array}{c}\text { Net Cash Outflow } \\
\text { (Yuan) }\end{array}$ & $\begin{array}{c}\text { Net Cash Inflow } \\
\text { (Yuan) }\end{array}$ & $\begin{array}{c}\text { Cumulative Net } \\
\text { Present Value (Yuan) }\end{array}$ \\
\hline 0 & 1.000 & 91.7 & 0.0 & -91.7 \\
1 & 0.909 & 11.2 & 62.8 & -44.8 \\
2 & 0.826 & 11.2 & 62.8 & -2.2 \\
3 & 0.751 & 11.2 & 62.8 & 36.6 \\
\hline
\end{tabular}

\section{Discussion}

\subsection{Biomass Energy Utilization Methods and Efficiency}

In this study, corncob was burned directly to make use of heat energy, and the thermal efficiency was $45.5 \%$. An important point to note is whether this kind of biomass use and thermal efficiency can be accepted. If compared with biomass power generation, biomass biogas, biomass ethanol, and other biomass energy utilization methods, this method is obviously not desirable as it has poor environmental benefits and low utilization rate. However, this view may be changed when considering and understanding the current situation of biomass energy utilization in China, especially in rural areas. 
China is an agricultural country, producing more than approximately 1000 million tons of crop straw in 2018 [23]. Chinese government has been strongly encouraging and promoting the development and utilization of biomass energy, such as bioelectricity, biogas, bioethanol, etc., but the process is not very smooth [24]. Especially in rural areas, villages are scattered, biomass energy density is low, and transportation is underdeveloped. It is difficult for enterprises and farmers to directly obtain economic benefits from the recycling of biomass. The large parts of agriculture residues are used with lower efficiency or wasted, with $37 \%$ being directly combusted by farmers, $15 \%$ lost during collection, and the remaining $20.5 \%$ discarded or directly burnt in the field [25]. It not only wastes resources, but also pollutes air, soil, and water. However, when biomass energy is used for greenhouse heating, the original biomass utilization rate close to 0 will be directly increased to $45.5 \%$, and the economic income of farmers will be increased indirectly. Therefore, the authors believe that the study will transfer the large-scale thermal energy utilization system of traditional biomass for industrial or construction fields to agricultural planting, with the characteristics of unrestricted scale, nearby and local use, which is suitable for the development needs of China's modern rural construction at this stage and is of great significance for the implementation of the strategy of comprehensive utilization of biomass resources.

\subsection{Limitations and Suggestions for Future Research}

In this experiment, the way of heating soil by a buried pipe network is used to control the indoor thermal environment of the greenhouse. Although the heating effect is obvious, there are limitations in this way. Because of the limitation of the rhizosphere temperature of plant growth, the maximum heating capacity of its heating system is limited. Therefore, if the heating system cannot meet the actual heating demand, what should we do? The authors believe that there are two ways here. One is to add additional auxiliary heating facilities, such as fan coils and hot air fans; further, the combined heating method is not affected by geographical and climatic conditions. The other is to use the heating system selectively according to the region; the hot summer and cold winter climate zone in China is the best, its temperature is above $0{ }^{\circ} \mathrm{C}$ for most of the time in winter. From the experimental results, it can ensure the safe production of a greenhouse. However, what kind of auxiliary facilities or other places to choose, and how the effect will be, need further study.

In this study, the parameter design of the system has not been fully optimized, and the experimental data are relatively small, but we cannot ignore the positive effect of the heating system. As we know, the heat exchange performance of soil and flue gas is the key to the whole system design. Therefore, we suggest that future research work should pay more attention to the influence of pipeline arrangement, buried depth, pipe diameter, pipe spacing, and other factors on system performance.

\section{Conclusions}

In this study, a biomass heating system was proposed to improve the air temperature and soil temperature inside greenhouses. An experimental platform of the heating system was built in a rural plastic greenhouse in Xiangtan City, Hunan Province, China. Through experimental data, we analyzed the heating performance, thermal efficiency, and economy of the biomass heating system. Some of the highlights are noted below:

(1) The heating effect of this biomass heating system is obvious. The average air temperature and surface soil temperature inside the heated plastic greenhouse were $12.2^{\circ} \mathrm{C}$, and $16.5^{\circ} \mathrm{C}$, which were $5.1{ }^{\circ} \mathrm{C}$ and $8.2{ }^{\circ} \mathrm{C}$ higher than that inside the unheated greenhouse. Therefore, the indoor thermal environment of the greenhouses with a biomass heating system can meet the off-season planting needs of most thermophilic cash crops.

(2) Based on the analysis of thermal efficiency, the thermal efficiency of the biomass heating system is $45.5 \%$, which is significantly better than the direct incineration of agricultural wastes. It is a new way of comprehensive utilization of rural biomass resources and has better environmental benefits and economic benefits. 
(3) The greenhouse with biomass heating system has better economic benefits. Through economic analysis, the heated plastic greenhouse can bring the minimum excess income for farmers of 26.4 yuan $/ \mathrm{m}^{2}$, with a $105 \%$ excess return rate every year. The dynamic investment recovery period of the heating system is 2.1 years.

These results indicate that the biomass heating system is an effective and economical method to improve the indoor thermal environment of greenhouses. Its application in rural areas of China is acceptable and has a good application prospect.

Author Contributions: Conceptualization, T.H. and H.L.; experiment, T.H., and H.L.; data curation, T.H. and G.Z.; writing-original draft preparation, T.H. and G.Z.; writing-review and editing, H.L. and F.X.; project administration, F.X.; funding acquisition, F.X. All authors have read and agreed to the published version of the manuscript.

Funding: This research was funded by the National Program on Key Research plan of China (Grant No. 2019YFD1101300).

Conflicts of Interest: The authors declare no conflicts of interest.

\section{References}

1. Lazaar, M.; Bouadila, S.; Kooli, S.; Farhat, A. Comparative study of conventional and solar heating systems under tunnel Tunisian greenhouses: Thermal performance and economic analysis. Sol. Energy 2015, 120, 620-635. [CrossRef]

2. Bai, Y.K. Study on the Fire-Pit and Underground Heating Exchange System of Solar Greenhouse. Ph.D. Thesis, Shenyang Agricultural University, Shenyang, China, 2007. (In Chinese).

3. Cuce, E.; Harjunowibowo, D.; Cuce, P.M. Renewable and sustainable energy saving strategies for greenhouse systems: A comprehensive review. Renew. Sustain. Energy Rev. 2016, 64, 34-59. [CrossRef]

4. Ahamed, M.S.; Guo, H.; Tanino, K. Energy saving techniques for reducing the heating cost of conventional greenhouses. Biosyst. Eng. 2019, 178, 9-33. [CrossRef]

5. Joudi, K.A.; Farhan, A.A. Greenhouse heating by solar air heaters on the roof. Renew. Energy 2014, 72, $406-414$. [CrossRef]

6. Gourdo, L.; Fatnassi, H.; Bouharroud, R.; Ezzaeri, K.; Bazgaou, A.; Wifaya, A.; Demrati, H.; Bekkaoui, A.; Aharoune, A.; Poncet, C.; et al. Heating canarian greenhouse with a passive solar water-sleeve system: Effect on microclimate and tomato crop yield. Sol. Energy 2019, 188, 1349-1359. [CrossRef]

7. Bargach, M.N.; Dahman, A.S.; Boukallouch, M. A heating system using flat plate collectors to improve the inside greenhouse microclimate in Morocco. Renew. Energy 1999, 18, 367-381. [CrossRef]

8. Bazgaou, A.; Fatnassi, H.; Bouharroud, R.; Elame, F.; Ezzaeri, K.; Gourdo, L.; Wifaya, A.; Demrati, H.; Tiskatine, R.; Bekkaoui, A.; et al. Performance assessment of combining rock-bed thermal energy storage and water filled passive solar sleeves for heating Canarian greenhouse. Sol. Energy 2020, 198, 8-24. [CrossRef]

9. Bazgaou, A.; Fatnassi, H.; Bouhroud, R.; Gourdo, L.; Ezzaeri, K.; Tiskatine, R.; Demrati, H.; Wifaya, A.; Bekkaoui, A.; Aharoune, A.; et al. An experimental study on the effect of a rock-bed heating system on the microclimate and the crop development under canarian greenhouse. Sol. Energy 2018, 176, 42-50. [CrossRef]

10. Gourdo, L.; Fatnassi, H.; Tiskatine, R.; Wifaya, A.; Demrati, H.; Aharoune, A.; Bouirden, L. Solar energy storing rock-bed to heat an agricultural greenhouse. Energy 2019, 169, 206-212. [CrossRef]

11. Benli, H.; Durmuş, A. Performance analysis of a latent heat storage system with phase change material for new designed solar collectors in greenhouse heating. Sol. Energy 2009, 83, 2109-2119. [CrossRef]

12. Berroug, F.; Lakhal, E.K.; El Omari, M.; Faraji, M.; El Qarnia, H. Thermal performance of a greenhouse with a phase change material north wall. Energy Build. 2011, 43, 3027-3035. [CrossRef]

13. Anifantis, A.S.; Colantoni, A.; Pascuzzi, S.; Santoro, F. Photovoltaic and hydrogen plant integrated with a gas heat pump for greenhouse heating: A mathematical study. Sustainability 2018, 10, 378. [CrossRef]

14. Pascuzzi, S.; Anifantis, A.S.; Blanco, I.; Scarascia Mugnozza, G. Electrolyzer performance analysis of an integrated hydrogen power system for greenhouse heating. A case study. Sustainability 2016, 8, 629. [CrossRef]

15. Benli, H. A performance comparison between a horizontal source and a vertical source heat pump systems for a greenhouse heating in the mild climate Elaziğ, Turkey. Appl. Therm. Eng. 2013, 50, 197-206. [CrossRef] 
16. Boughanmi, H.; Lazaar, M.; Guizani, A. A performance of a heat pump system connected a new conic helicoidal geothermal heat exchanger for a greenhouse heating in the north of Tunisia. Sol. Energy 2018, 171, 343-353. [CrossRef]

17. Ozgener, O.; Hepbasli, A. Experimental performance analysis of a solar assisted ground-source heat pump greenhouse heating system. Energy Build. 2005, 37, 101-110. [CrossRef]

18. Nemś, A.; Nemś, M.; Świder, K. Analysis of the possibilities of using a heat pump for greenhouse heating in Polish climatic conditions-A case study. Sustainability 2018, 10, 3483. [CrossRef]

19. Chai, L.; Ma, C.; Ni, J.-Q. Performance evaluation of ground source heat pump system for greenhouse heating in northern China. Biosyst. Eng. 2012, 111, 107-117. [CrossRef]

20. Chau, J.; Sowlati, T.; Sokhansanj, S.; Preto, F.; Melin, S.; Bi, X. Economic sensitivity of wood biomass utilization for greenhouse heating application. Appl. Energy 2009, 86, 616-621. [CrossRef]

21. Zhang, B.; Fan, X.; Liu, M.; Hao, W. Experimental study of the burning-cave hot water soil heating system in solar greenhouse. Renew. Energy 2016, 87, 1113-1120. [CrossRef]

22. JB/T10297-2014, Design Regulation of Greenhouse Heating System: Mechanical Industry Standard of the People's Republic of China; Machinery Industry Press: Beijing, China, 2014. (In Chinese)

23. Guan, Y.; Tai, L.; Cheng, Z.; Chen, G.; Yan, B.; Hou, L. Biomass molded fuel in China: Current status, policies and suggestions. Sci. Total Environ. 2020, 724, 138345. [CrossRef] [PubMed]

24. Chen, L.; Li, X.; Wen, W.; Jia, J.; Li, G.; Deng, F. The status, predicament and countermeasures of biomass secondary energy production in China. Renew. Sustain. Energy Rev. 2012, 16, 6212-6219. [CrossRef]

25. Liu, H.; Jiang, G.; Zhuang, H.; Wang, K. Distribution, utilization structure and potential of biomass resources in rural China: With special references of crop residues. Renew. Sustain. Energy Rev. 2008, 12, 1402-1418. [CrossRef]

(C) 2020 by the authors. Licensee MDPI, Basel, Switzerland. This article is an open access article distributed under the terms and conditions of the Creative Commons Attribution (CC BY) license (http://creativecommons.org/licenses/by/4.0/). 